\title{
More on the Gettier Problem and Legal Proof: Unsafe Nonknowledge Does Not Mean that Knowledge Must Be Safe
}

Michael S. Pardo

University of Alabama - School of Law, mpardo@law.ua.edu

\section{Recommended Citation}

Michael S. Pardo, More on the Gettier Problem and Legal Proof: Unsafe Nonknowledge Does Not Mean that Knowledge Must Be Safe, (2011).

Available at: https://scholarship.law.ua.edu/fac_working_papers/291

This Working Paper is brought to you for free and open access by the Faculty Scholarship at Alabama Law Scholarly Commons. It has been accepted for inclusion in Working Papers by an authorized administrator of Alabama Law Scholarly Commons. 


\section{THE UNIVERSITY OF ALABAMA SCHOOL OF LAW}

More on the Gettier Problem and Legal Proof: Unsafe Nonknowledge Does Not Mean That Knowledge Must Be Safe

Michael S. Pardo

17 LEGAL THEORY (forthcoming 2011)

This paper can be downloaded without charge from the Social Science Research Network Electronic Paper Collection: http://ssrn.com/abstract=1846765 


\title{
More on the Gettier Problem and Legal Proof: Unsafe Nonknowledge Does not Mean that Knowledge Must be Safe
}

\author{
Michael S. Pardo*
}

In The Gettier Problem and Legal Proof, ${ }^{1}$ I argued that epistemic conditions that undermine knowledge in Gettier-type cases also potentially undermine legal verdicts. ${ }^{2}$ For this reason, I argued, there is a deeper connection between knowledge and legal proof than is typically presupposed or argued for in the scholarly legal literature. To support these claims, I presented several examples illustrating how conditions that render epistemically justified beliefs merely accidentally true (and thus disqualify them as cases of genuine knowledge) may also render evidentially well-supported verdicts merely accidentally true for similar reasons. Such “Gettier-ized” verdicts, I contended, fail to realize the epistemic goal or aim of legal proof. Thus, I concluded, legal proof includes something like a knowledge requirement—in the sense that legal verdicts aim not only at truth and sufficient evidential support but also, as with knowledge, an appropriate connection between their truth and justifying evidential support. ${ }^{3}$

\footnotetext{
* Henry Upson Sims Professor of Law, University of Alabama School of Law.

16 Legal THEORY 37 (2010).

2 See Edmund L. Gettier, Is Justified True Belief Knowledge?, 23 AnALYsIs 121 (1963)

${ }^{3}$ In drawing attention to this connection, I also conceded that successful legal verdicts may fail to qualify as knowledge for other reasons.
} 
This conclusion is compatible with different ways of articulating further epistemological details, ${ }^{4}$ and the argument that supports it does not depend on any novel or particularly controversial conceptions of knowledge, justification, or truth. ${ }^{5}$ Nor does it depend on a novel or particularly controversial analysis of the Gettier problem (or possible solutions). If Gettier conditions are a problem for both knowledge and legal verdicts—and they are a problem for similar reasons — then this supports my central claim about the nature of legal proof.

Further analysis may clarify these related problems in both epistemology and law. In epistemology, much well-known work has been done toward this end. Although there is no consensus regarding the Gettier problem and the manifold issues with which it intersects, a voluminous literature has illuminated the issues and its contours. ${ }^{6}$ In law, this is decidedly less so. One ancillary theme of my article is the need for more conceptual work regarding the epistemology of law and legal proof. My article was intended as a step in this direction.

In his thoughtful reply to my article, ${ }^{7}$ Mark McBride continues this conceptual work by focusing on the epistemic concept of safety as it applies to legal proof. I am grateful for such an interesting and engaging discussion of my work.

McBride argues that my analysis depends on an account of legal knowledge in which safety is a necessary condition; he then purports to show "some difficulties" for this account that

\footnotetext{
${ }^{4}$ For example, the analysis runs orthogonal to, and does not depend on, many of the competing claims made by internalists, externalists, reliabilists, coherentists, virtue theorists, and naturalists regarding knowledge and justification.

${ }^{5}$ Of course, to say virtually anything at all about knowledge will invoke some contested presuppositions about these concepts, but given my focus I relied on relatively uncontroversial aspects.

${ }^{6}$ For an overview of the literature, see William G. Lycan, On the Gettier Problem Problem, in EPISTEMOLOGY FUTURES 148 (Stephen Hetherington ed., 2006).

${ }^{7}$ Mark McBride, Reply to Pardo: Unsafe Legal Knowledge?, _ Legal Theory _ (2011).
} 
"put pressure" on my central claim. ${ }^{8}$ McBride attempts to demonstrate these difficulties with an example (Insecure Mafia) that purports to undermine a safety requirement by appearing to be both unsafe and a successful case of (legal) knowledge. He closes by presenting a trilemma, according to which I must conclude (1) the example is not a case of knowledge; (2) the verdict in the example is safe; or (3) safe knowledge is not the goal or aim of legal proof. ${ }^{9}$ Each option, McBride concludes, "has its drawbacks."10

Neither McBride’s specific example nor the more general analysis undermines the central claim of my article. They do, however, further clarify and illuminate epistemological issues underlying my central claim in ways that are useful and instructive. In this response, I explain how McBride's reply extends the analysis in my article but why it does not pose a difficulty for, put pressure on, or otherwise challenge my central claim.

\section{Safety and a Proposed Trilemma}

The epistemic concept of safety did not feature prominently in my article. My central argument concerned a more general claim: epistemic conditions that undermine knowledge in Gettier cases also potentially undermine the success of legal verdicts. In discussing one example of a "Gettier-ized” verdict, however, I explained that the verdict was problematic "primarily

\footnotetext{
${ }^{8}$ Id. at 1 [page numbers refer to McBride’s manuscript].

${ }^{9}$ Id. at 6 ("This all suggests the following trilemma ... (1) Retain his central claim that (safe) knowledge is the goal or aim of legal proof and deny Insecure-Mafia is a case of knowledge. (2) Retain his central claim that (safe) knowledge is the goal or aim of legal proof and deny Insecure-Mafia is a case of unsafety. ${ }^{9}$ Or: (3) Withdraw his central claim that (safe) knowledge is the goal or aim of legal proof.”)

${ }^{10} I d$.
} 
because it is unsafe." ${ }^{11}$ Similarly, I also claimed more generally that non-Gettier-ized verdicts are better and more just than Gettier-zed ones "because they are safer."12 Keenly picking up on these two assertions, McBride explores a safety requirement in more detail in the legal context and finds difficulties with it.

Here is the example for which I invoked the concept of safety:

Fake Cabs: The plaintiff files a lawsuit against the defendant, who owns and drives the only taxicab in town, claiming she was hit by the defendant's cab while crossing the street. She saw the cab drive away but did not see the driver. A video camera at the intersection filmed the accident, and it shows what appears to be a cab (but not the driver) hitting the plaintiff, exactly as she claimed. Now, suppose the car in the video really is the defendant's, but also that - unknown to the jury - along with his real cab there are hundreds of other cars in the town that look identical to his cab. The jury finds for the plaintiff based on the video. ${ }^{13}$

I explained that this verdict is problematic (i.e., it fails to meet the epistemic goal or aim of legal proof) because it is unsafe. Because, according to my analysis, the unsafe circumstances in the example undermine knowledge and the verdict, McBride concludes that safety is a necessary condition for my accounts of both knowledge and successful verdicts. Accordingly, an example of unsafe conditions that results in both knowledge and a successful verdict poses a challenge to accounts that rely on safety as a necessary condition.

\footnotetext{
${ }^{11}$ See supra note 1, at 52 n.61. In my article, I discussed four other examples of potentially Gettier-ized verdicts and did not analyze their potential problems in terms of safety.

${ }^{12}$ Id at 56 n. 81.

${ }^{13}$ Id. at 52.
} 
McBride unpacks the concept of safety and then presents an example (Insecure Mafia) that purports to pose such a challenge. In the epistemic context, "safe" and "unsafe" refer to whether a belief would be true in similar or nearby counterfactual possible worlds. ${ }^{14}$ As McBride puts it:

UNSAFETY: In a number of similar possible worlds a subject, S, would have believed a proposition, p, on the same basis and been in error.

SAFETY: It's not the case that: In a number of similar possible worlds a subject, S, would have believed a proposition, p, on the same basis and been in error.

He translates this to the context of legal verdicts as follows:

JURY-UNSAFETY: In a number of similar possible worlds the jury would have reached the same result on the same basis and been in error.

JURY-SAFETY: It's not the case that: In a number of similar possible worlds the jury would have reached the same result on the same basis and been in error.

McBride then presents a putative counterexample to a safety requirement and proposes a trilemma. The example purports to provide a verdict that is both unsafe and a case of knowledge. The first horn of the trilemma is to maintain that the verdict is not a case of knowledge. The second horn is to maintain that the verdict is safe. The third horn is to withdraw the "central claim" that safety is a necessary requirement and that safe knowledge is the goal or aim of legal proof. Here is the example:

\footnotetext{
${ }^{14}$ This epistemic notion of safety is distinct from the British legal standard of an "unsafe verdict," which refers to criminal convictions in which there is lingering doubt. For a discussion of the latter, see D. Michael Risinger, Unsafe Verdicts: The Need for Reformed Standards for the Trial and Review of Factual Innocence Claims, 41 HOUSTON LAW REviEW 1281 (2004). Epistemic safety is also distinct from the related modal notion of sensitivity. For a discussion of the distinction, see Duncan Pritchard, Safety, Sensitivity, and Antiluck Epistemology, in THE OXFORD HANDBOOK OF SKEPTICISM 437 (John Greco ed., 2008).
} 
Insecure-Mafia: The chief prosecution witness, Amoruso, an honest and reliable citizen, is ready to truthfully provide damning evidence against the guilty defendant, Baggio, a member of the Mafia - such evidence guaranteeing a guilty verdict. However, InsecureMafia, Mafia’s rivals, have reason to believe that Baggio’s brother, Carbone, may be a member of the jury, and are certain that Carbone, if on the jury and presented with damning evidence against Baggio, will successfully obstruct a guilty verdict. So as not to lose face (by dint of a rival Mafioso going scot-free and being seen to do so), InsecureMafia devise the following plan: Should Carbone appear on the jury on the first day of trial, Insecure-Mafia will, overnight, switch Baggio for Twin-Baggio (an unrelated exact look-a-like of Baggio) - Twin-Baggio becomes the defendant -, and inform only Carbone of the switch (who is no longer motivated to obstruct the guilty verdict). Baggio has no incentive to reveal the switch, and Twin-Baggio is paid handsomely by InsecureMafia in return for his silence. Amoruso would then, unawares, untruthfully provide the same damning evidence against Twin-Baggio, thereby guaranteeing an unjust guilty verdict against Twin-Baggio and saving Insecure-Mafia’s face - at least it would seem like a rival Mafioso had been sent down. Carbone, however, is not on the jury. At the final hurdle in the tests for jury-membership - having passed 99 of the 100 tests - it emerges that Carbone is Baggio’s brother, and Carbone is dismissed. So the plan is not initiated, and the case proceeds normally: Amoruso provides true damning evidence against Baggio, and the jury convicts Baggio on the basis of Amoruso’s testimony. Based on this example, McBride concludes that taking any of the three horns of the trilemma "has its drawbacks." 


\section{Why The Third Lemma is not a Horn}

The verdict in Insecure Mafia is a case of knowledge in the sense in which I claimed knowledge is the goal or aim of legal proof. It is true, supported by sufficient evidence, and is not "Gettier-ized" (unlike the examples I presented in my article). Therefore, the verdict is successful. This result is consistent with the analysis in my article. What then of the proposed trilemma?

The first horn— concluding the verdict is not a case of knowledge—should be rejected for the reasons just given. Because the verdict is not "Gettier-ized," 15 it does not suffer from the epistemic problems that I claimed undermine the (true and justified) verdicts in the examples I discussed. $^{16}$

The second horn—concluding the verdict is safe—is more promising but still has some “drawbacks.” In arguing about whether the verdict is safe or unsafe, it is important to acknowledge some difficulties in applying these concepts. Delineating safe from unsafe conditions requires difficult line drawing along two different dimensions. First, one has to decide which counterfactual possible worlds are to count as nearby or similar and which are to count as remote. Second, one has to decide how many false beliefs (verdicts) in similar possible worlds render the belief (verdict) unsafe: one, many, most?

These difficulties notwithstanding, one plausible response to the proposed trilemma of Insecure Mafia is to embrace the second horn. One might argue that the verdict is safe because

\footnotetext{
15 That is, there does not appear to be the sort of accidental connection between the verdict's truth and justification that is present in Gettier situations. Although the facts could be altered to Gettier-ize this verdict, McBride is correct that I claimed verdicts ought not be Gettier-ized, not that they ought not be Gettier-ize-able.

16 The verdict would not qualify as knowledge if the defendant contested identity and presented a plausible case that he is not the person the prosecution claims him to be. See Ronald J. Allen, Factual Ambiguity and a Theory of Evidence, 88 NORTHWESTERN UNIVERSITY LAW REVIEW 604 (1994),
} 
the possible world in which the belief is false is one in which the defendant's brother serves on the jury. Thus, so the argument would go, this is just too dissimilar to the actual world that it need not be taken seriously in the safety analysis. Likewise, even if the example counts as a similar possible world, one might also argue that the verdict is safe by employing a safety principle that considers a verdict safe if it is true in most (but not all) similar possible worlds. Thus, even if the verdict is false in this one possible world, it is true in most other possible worlds in which the defendant's brother does not serve on the jury. Although plausible responses may be constructed along these lines, I avoid this second path for a number of reasons. Given the difficulties noted above, such a response would likely devolve into arbitrary line drawing about what counts as safe and unsafe. And even if the verdict in Insecure Mafia could be defended as "safe," other examples involving "unsafe” (legal) knowledge could likely be constructed.

Therefore, I embrace the third path of the proposed trilemma, which I conclude is not really a horn at all. The third lemma is to withdraw the "central claim" that safety is a necessary condition for knowledge and successful verdicts. This was not my central claim. My claim was that epistemic conditions that undermine knowledge in Gettier cases also potentially undermine legal verdicts. In support of this claim, I presented an example (Fake Cabs) in which the verdict and knowledge are undermined because the epistemic conditions render the verdict unsafe. And, in the example, it is extremely unsafe. ${ }^{17}$ Indeed, there are hundreds of similar possible worlds in which the verdict is reached on the same basis and in error; had it been any of the other identicallooking cars hitting the plaintiff in the video, the verdict would be false.

\footnotetext{
${ }^{17}$ Regardless of how one draws the line between "safe" and "unsafe," the verdict in this example appears to fall on the "unsafe" side.
} 
Contrast this with the epistemic conditions in Insecure Mafia in which the challenge to the safety of the verdict is the possibility of an unrealized elaborate plot. The differences between the two cases are instructive. A verdict may be so unsafe (as in Fake Cabs) that it fails its epistemic goal or aim and fails to qualify as knowledge—but this does not necessarily imply that any time there is a (similar) possible world in which the jury decides on the same basis and is in error (as in Insecure Mafia) the verdict fails and fails to qualify as knowledge. To sharpen the distinction: consider the difference between an eyewitness who correctly identifies a defendant but (1) would have declared a positive identification (falsely) if presented with anyone else of the same race and sex and roughly the same age as the defendant; or (2) would have declared a positive identification only if presented with the defendant or with someone cleverly disguised to look exactly like the defendant. To recognize an epistemic problem in the first type of case does not commit one to concluding that the second type of case is likewise problematic.

The central claim of my article concerns cases like the first type. I claimed that Gettierized conditions may undermine the epistemic success of legal verdicts. Such conditions may occur when a verdict is so unsafe that, even if true, it is merely accidentally true (and not a case of knowledge). This claim is compatible with cases of the second type being successful verdicts and genuine cases of knowledge (even though unsafe). In drawing attention to the possibility of cases of the second type, McBride provides a useful amendment to my article, not a challenge to my central claim. Because of the connection between knowledge and legal proof, if knowledge can be unsafe, then successful verdicts may also be unsafe. The extent to which unsafe verdicts may sometimes qualify as knowledge and satisfy the epistemic goal or aim of legal proof is a topic in need of further analysis and will likely depend on the details of how "safe" and "unsafe" are specified. But under virtually any conception of these concepts, some verdicts are so unsafe 
that they fail to qualify as knowledge and, for similar reasons, they fail the epistemic goal or aim of legal proof. 